
Managing High-Frequency Hearing

\title{
Loss: A Review
}

\author{
Andrea Simpson, PhD
}

Frequency-lowering technology has been around for decades. The primary aim-namely, that of providing high-frequency information to those with severe highfrequency hearing loss-addresses a clinical need most conventional hearing devices are still unable to provide. Early studies with frequency-lowering technology reported mostly unfavorable results, and the devices never gained clinical popularity. However, as hearing aid (HA) technology becomes ever more sophisticated, it is appropriate to reconsider whether frequency-lowering HAs should be an amplification choice in those with high-frequency hearing loss. Recent research is yielding promise with people who wear frequencylowering devices showing improved speech perception. Questions remain regarding patient candidacy and whether auditory training may result in better outcomes. The author also discusses future clinical directions and research needs for frequency lowering.

Keywords: frequency lowering; transposition; frequency compression; frequency shifting; hearing aids

\section{Introduction}

A significant percentage of individuals with hearing loss have some access to low-frequency sounds, with limited access to higher frequency sounds (Davis, 1995; for the purposes of this article, we'll define higher frequencies as $1 \mathrm{kHz}$ and above). These individuals often miss out on high-frequency components of speech, such as consonant sounds, and can have difficulties understanding speech in background noise. High-frequency information is particularly important for children who use these cues to learn articulation of sounds as well as many grammatical rules.

Depending on the configuration and severity of the hearing loss, simple amplification is often not effective in restoring intelligibility of high-frequency sounds (Ching, Dillon, \& Byrne, 1998; Hogan \& Turner, 1998; Murray \& Byrne, 1986; Rankovic, 1991). This lack of benefit of high-frequency

From the University of Manchester, Manchester, United Kingdom.

Address correspondence to: Andrea Simpson, Ellen Wilkinson Building, University of Manchester, Manchester, M139PL, U.K.; andreavee@gmail.com. amplification, when found, has been attributed by many researchers to the presence of nonfunctioning inner hair cells over a certain region of the cochleathat is, dead regions (Baer, Moore, \& Kluk, 2002; Moore \& Glasberg, 1997; Vickers, Baer, \& Moore, 2001).

For individuals with severe or profound hearing loss at high frequencies, it is simply not possible to restore audibility to normal levels using only amplification. As conventional hearing aids (HAs) have largely failed to provide such individuals with highfrequency cues, alternative methods of signal processing have been considered that present information from high-frequency regions of speech to lower frequency regions. The method to be discussed in this article is commonly referred to as frequency lowering (also known as frequency shifting, frequency compression, or transposition. These terms are often used interchangeably when describing frequencylowering techniques). For convenience, the second section of this review describes these processing techniques under the headings of channel vocoders, slow playback, transposition, and frequency compression. The differences between the methods are summarized in Table 1. Although the processing techniques implemented in frequency-lowering 
Table 1. Overview of the Different Ways of Implementing Frequency Lowering in Signal Processing

\begin{tabular}{|c|c|c|c|}
\hline & Description & Advantages & Disadvantages \\
\hline Vocoding & $\begin{array}{l}\text { Envelopes of signals in high-frequency } \\
\text { bands are estimated and used to modu- } \\
\text { late the amplitudes of an equal number } \\
\text { of signal generators, which produce } \\
\text { either pure tones or narrow-band } \\
\text { noises at frequencies lower than those } \\
\text { of the corresponding filters }\end{array}$ & $\begin{array}{l}\text { Flexibility of processing } \\
\text { parameters at time of } \\
\text { design }\end{array}$ & $\begin{array}{l}\text { Early vocoders didn't distinguish } \\
\text { between voiced and voiceless } \\
\text { sounds, nonspeechlike sound } \\
\text { quality }\end{array}$ \\
\hline Slow playback & $\begin{array}{l}\text { Records segments of the speech signal } \\
\text { and then plays these segments back at } \\
\text { a slower speed than that used in the } \\
\text { original recording }\end{array}$ & $\begin{array}{l}\text { Preserves harmonic } \\
\text { relationship between } \\
\text { frequency components }\end{array}$ & $\begin{array}{l}\text { Segment deletion can cause distor- } \\
\text { tion or discard useful speech } \\
\text { information, signal stretched in } \\
\text { time }\end{array}$ \\
\hline Transposition & $\begin{array}{l}\text { Shifts high-frequency sounds to lower } \\
\text { frequencies and adds transposed signal } \\
\text { to unprocessed lower frequency signal }\end{array}$ & $\begin{array}{l}\text { More natural sound quality, } \\
\text { preserves harmonic rela- } \\
\text { tionship between fre- } \\
\text { quency components }\end{array}$ & $\begin{array}{l}\text { If continuously active, overlap of } \\
\text { high and low frequencies can } \\
\text { mask useful low-frequency infor- } \\
\text { mation, can transpose unwanted } \\
\text { high-frequency background noise }\end{array}$ \\
\hline $\begin{array}{l}\text { Nonlinear } \\
\text { frequency } \\
\text { compression }\end{array}$ & $\begin{array}{l}\text { Lower frequencies unprocessed, higher } \\
\text { frequencies compressed in greater } \\
\text { amounts }\end{array}$ & $\begin{array}{l}\text { More natural sound quality, } \\
\text { preservation of vowel } \\
\text { intelligibility, no overlap } \\
\text { in frequency information }\end{array}$ & $\begin{array}{l}\text { Does not preserve harmonic rela- } \\
\text { tionship between frequency } \\
\text { components }\end{array}$ \\
\hline $\begin{array}{l}\text { Frequency } \\
\text { shifting }\end{array}$ & $\begin{array}{l}\text { Lowers all frequency components down- } \\
\text { ward by a constant factor }\end{array}$ & $\begin{array}{l}\text { Preserves harmonic } \\
\text { relationship between } \\
\text { frequency components }\end{array}$ & $\begin{array}{l}\text { Lowers pitch of speaker, unnatural } \\
\text { sound quality }\end{array}$ \\
\hline
\end{tabular}

schemes differ, all have the same aim of restoring high-frequency information to the individual.

The last comprehensive review on frequency lowering as a rehabilitative option for hearing impairment was written 30 years ago by Braida et al. (1979). Results at that time were largely unfavorable, with frequency lowering showing either no change or a reduction in speech understanding. Explanations for this may have been that the frequency-lowering schemes implemented at the time were created using older technology, resulting in poor and unnatural sound quality for the listener. In addition, the large majority of hearing-impaired participants in these early studies had very little measurable hearing at all frequencies. As most participants had bilateral profound hearing loss, the benefits of the processing would have been marginal.

With more sophisticated processing, frequency lowering has gained renewed interest and has been incorporated in several commercially available hearing devices. A review of past and present studies with frequency-lowering devices is provided in the third section of the article. With increased access to frequency-lowering devices, further questions regarding this technology are now being raised.
A summary of studies using frequency lowering for adults and children is given in Tables 2 and 3 , respectively. Future research needs for frequencylowering devices are discussed in the fourth section of the article.

\section{Frequency-Lowering Schemes}

This section aims to describe the more commonly used methods of implementing frequency lowering-namely, channel vocoders, slow playback, transposition, and frequency compression. Each of these schemes have both advantages and limitations in terms of sound quality for the person involved. A summary of these together with a description of each method can be found in Table 1.

\section{Channel Vocoders}

Vocoding describes a technique of speech processing where the signal is divided into frequency bands. These bands are modified, added together, and presented to the listener. Specifically, the signal is divided into bandpass analysis filters, and the signal envelope is extracted from each filter (see Figure 1). 


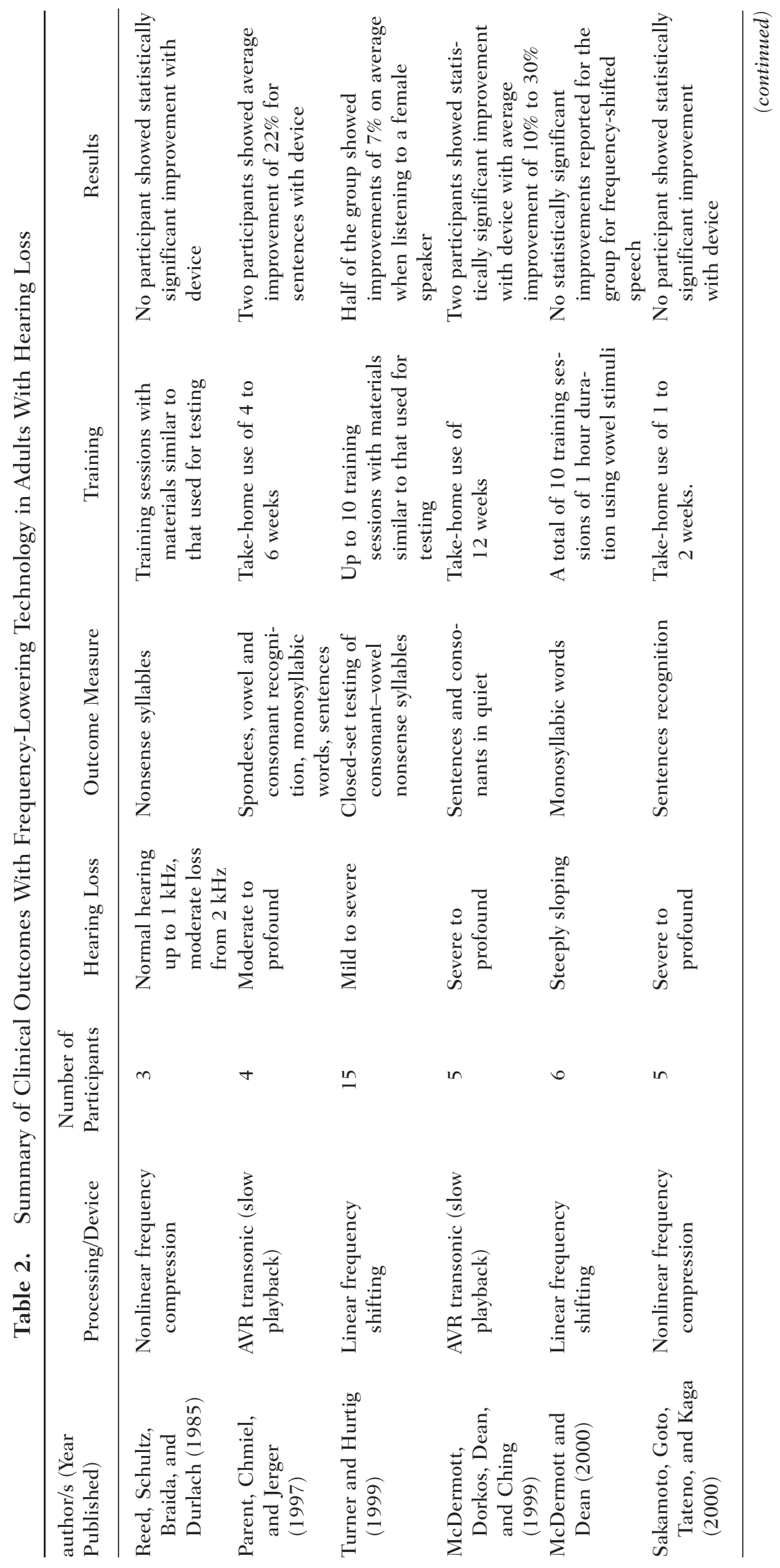




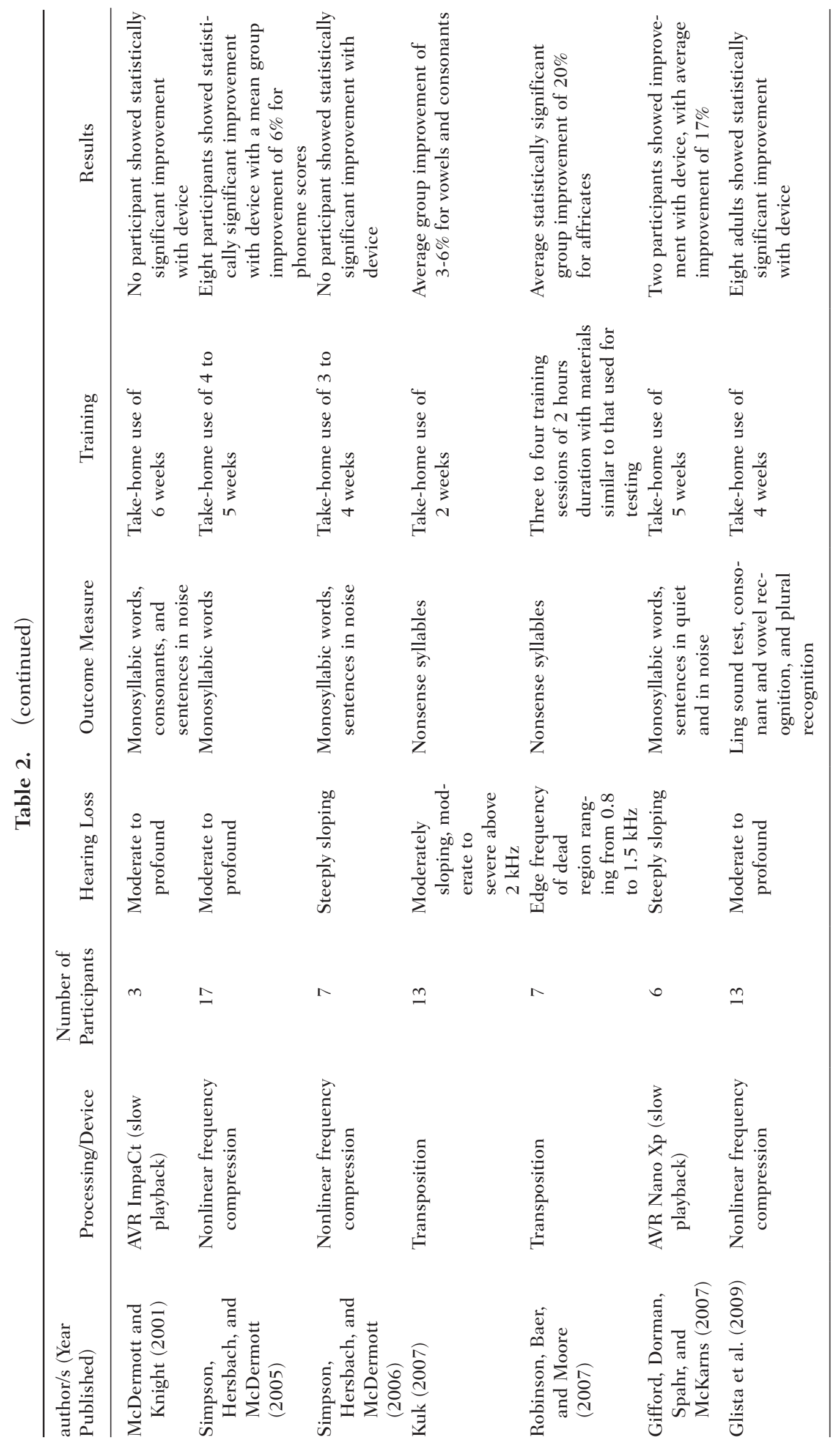




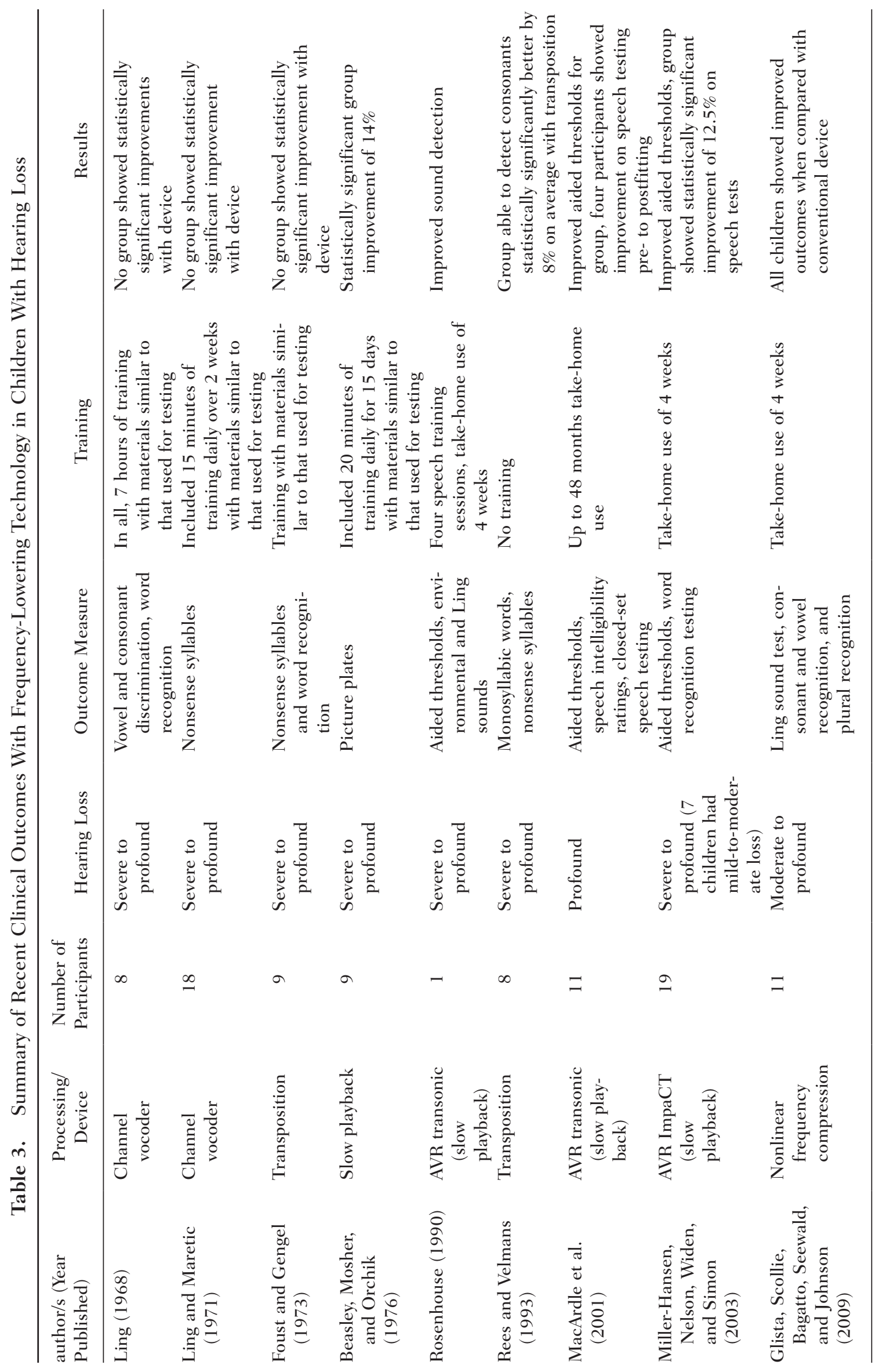




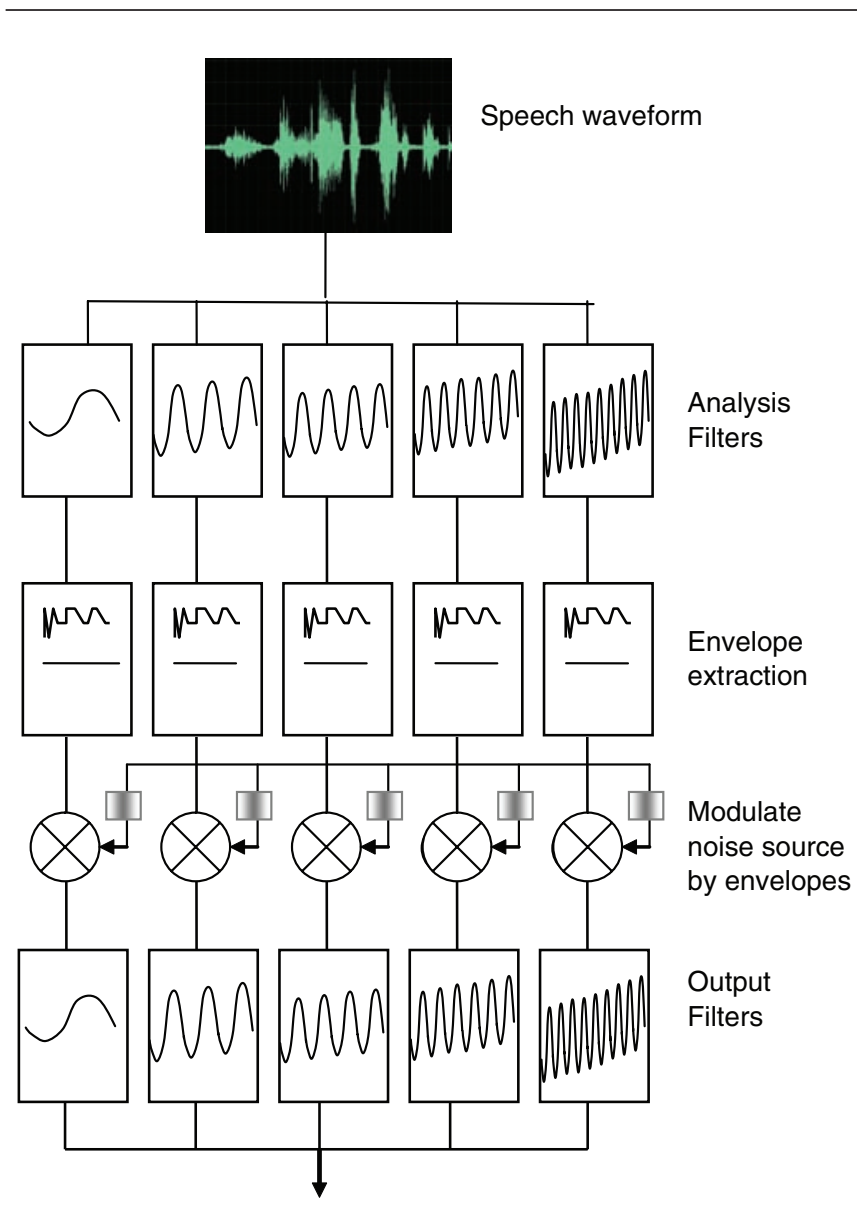

Figure 1. Block diagram representing signal processing in a noise vocoder simulation.

An acoustic source, usually noise, is modulated by the envelopes. The level of the noise in each filter is determined by the level of the signal envelope in the corresponding analysis filter. The modulated noise bands are then summed and presented to the listener. When frequency lowering, the envelopes of signals in high-frequency bands are estimated and used to modulate the amplitudes of an equal number of signal generators, which produce either pure tones or narrow-band noises at frequencies lower than those of the corresponding filters. The unmodified low-frequency signals are then combined with the outputs of the signal generators. In this way, aspects of the spectral shape are preserved during the processing. To the author's knowledge, no commercial devices have implemented channel vocoding as a method for frequency lowering.

\section{Slow Playback}

Slow playback (Beasley, Mosher, \& Orchik, 1976; Bennett \& Byers, 1967; Davis, 2001) describes a method of frequency lowering that records segments of the speech signal and then plays these segments back at a slower speed than that used in the original recording, with the resulting output signal lengthened in time and lowered in frequency. The method has the advantage of retaining the harmonic relationship between frequency components and the disadvantage of stretching the signal in time. This can cause the input and output signals to be desynchronized in time, and some distortion can occur as samples of the signal have to be deleted to reduce this side effect of the processing.

AVR Sonovations releases commercially available hearing instruments that incorporate such processing. The latest products at the time of writing are the Nano $\mathrm{Xp}$, ImpaCt $\mathrm{Xp}$, and the Logicom Xp. Incoming signals dominated by components at frequencies above $2.5 \mathrm{kHz}$ are moved down in frequency and compressed in bandwidth by a factor that is programmable for each person. If the input signal is not dominated by frequencies above $2.5 \mathrm{kHz}$, then signals are amplified with no frequency lowering.

\section{Transposition}

Frequency transposition shifts high-frequency sounds to lower frequencies and adds the transposed signal to an unprocessed lower frequency signal (see Figure 2 ). The method became the first frequency-lowering technique to be implemented into a commercial HA-the Oticon TP 72 (Johansson, 1961). The device consisted of two channels. Frequencies of 0.15 to $3 \mathrm{kHz}$ were amplified in a conventional manner. Higher frequencies between 4 and $8 \mathrm{kHz}$ were passed through a nonlinear modulator and converted into low-frequency noise below $1.5 \mathrm{kHz}$. A major shortcoming of the scheme was that the processing did not allow for the preservation of significant details of the spectral shape of the incoming signals.

Another transposing scheme, the Frequency REcoding Device (FRED), developed by Velmans (1973, 1974), did preserve some information about high-frequency spectral shape. The scheme divided the incoming signal into low-pass and high-pass bands, with a crossover frequency of $4 \mathrm{kHz}$. A constant value of $4 \mathrm{kHz}$ was subtracted from each frequency present in the high-pass band and the resulting signals were mixed with those obtained from the low-pass band.

Transposition has also been explored by Robinson, Baer, and Moore (2007) who used estimates of the 
INPUT SIGNAL

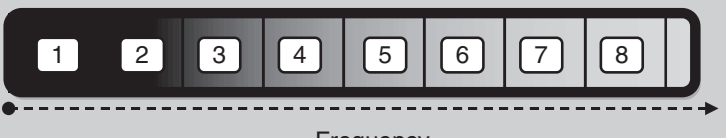

Frequency

A. Transposition

B. Frequency shifting and frequency compression

OUTPUT SIGNAL

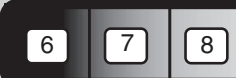

Overlap in shifted and unshifted signal

\section{\begin{tabular}{|ll|l|l|l|}
1 & 2 & 3 & 4 & 5 \\
\hline
\end{tabular}}

Frequency (i) Linear frequency shift (Equal amount of lowering)

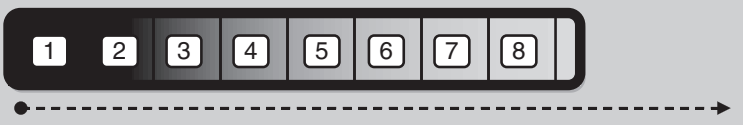

(ii) Nonlinear frequency compression(Lowering more severe at higher frequencies)

\section{\begin{tabular}{ll|l|l|l|l|l|l|}
1 & 2 & 3 & 4 & 5 & 6 & 7 & 8 \\
\hline
\end{tabular}}

Frequency

Figure 2. Schematic representation of transposition and frequency compression as methods of frequency lowering.

edges of dead regions to determine the starting point of transposition. A frequency band well within the participant's dead region was transposed into a frequency band just above the edge frequency of the dead region and overlapped with speech that was lowpass filtered. Frequencies below the edge frequency were amplified but not transposed, and transposition only occurred if the incoming signal was dominated by high frequencies.

At the time of writing, the latest commercially available transposing device is the Widex Inteo's audibility extender (AE), which incorporates frequency transposition (Kuk, 2007; Kuk et al., 2006; Kuk, Keenan, Peeters, Lau, \& Crose, 2007). The audiogram is used to determine the starting frequency at which transposition begins. The first frequency above $1.6 \mathrm{kHz}$ that is above $70 \mathrm{~dB}$ HL in threshold and has a slope greater than $10 \mathrm{~dB} /$ octave (for frequencies between 0.5 and $4 \mathrm{kHz}$ ) is selected as the starting frequency. This starting frequency can also be manually selected by the clinician from 0.63 to $6 \mathrm{kHz}$ in one-third octave intervals. Frequencies below the starting frequency are amplified but not transposed.
Higher frequencies up to two octaves above the starting frequency are analyzed by the HA. A narrow range of frequencies with the highest intensity levels within this range are selected, transposed by one octave, and overlapped with the lower frequency signal below the starting frequency. The clinician can adjust the level of the transposed signal and select a transposition range of one or two octaves above the starting frequency.

As low-frequency information is usually not affected by transposition schemes, this processing has the advantage of a more natural sound quality. In addition, the ratio between frequency components in the high-frequency transposed region is usually preserved. The main disadvantage of transposition is that the overlap of high- and low-frequency information can be detrimental as the added high-frequency information can mask useful low-frequency information as well as transposing unwanted high-frequency background noise. Many transposing schemes attempt to avoid these problems by ensuring that transposition is only active when the input signal contains mostly high-frequency information. 


\section{Frequency Compression}

Frequency compression reduces the bandwidth of the outgoing signal. It can be linear (also known as proportional shifting) or nonlinear (nonproportional shifting). Linear frequency shifting lowers all frequency components downward by a constant factor and has the advantage of preserving spectral information as the ratios among the frequency components are left unchanged by the processing. In this way, the relations between the frequencies of the formant peaks in speech remain constant. These ratios may be particularly important cues for the recognition of vowels in speech (Neary, 1989). The pitch of the speech signal, however, is lowered, and the speech may therefore sound unnatural. For example, a female voice may sound more like a male voice. To date, linear frequency shifting has not been implemented in a take-home device, most likely because of the unnatural sound quality.

Nonlinear frequency compression reduces the bandwidth of a speech signal (see Figure 2) by applying increasing amounts of frequency lowering to relatively high input frequencies (Sekimoto \& Saito, 1980). Advantages for such a scheme include no overlap between the shifted and unshifted signals, and low- and midfrequency information remains preserved as the whole first-formant frequency range is left unchanged by the processing. However, the nonlinearity of the compression means that frequency ratios (including harmonic ratios) for those high frequencies that were compressed are not preserved. Speech perception could, therefore, be negatively affected if the cutoff frequency of compression was decreased to include lower frequencies. The Phonak Naida is an example of a commercially available device that incorporates such processing.

\section{Patient Benefits With Frequency Lowering}

\section{Channel Vocoders}

Early attempts at frequency lowering used noise vocoder techniques (Dudley, 1939; Lippmann, 1980; Posen, Reed, \& Braida, 1993). Much of the testing was conducted with normally hearing participants in laboratory settings. Participants were provided with training, usually of the same format as the test material, and presented with vocoded speech that had been lowered in frequency. Speech intelligibility was then measured over time. In general, normally hearing participants could adapt to the vocoded signal, with most studies showing an improvement in scores over time with training (Denes, 1967). In the most recent of these studies, Lippmann (1980) simulated hearing loss in seven normally hearing participants by presenting them with speech that had been low-pass filtered at $0.8 \mathrm{kHz}$. High-frequency information was provided by modulated highfrequency bandpass noise with center frequencies of $1.14,1.82,2.86$, and $4.56 \mathrm{kHz}$, which were transposed into output bands with center frequencies of $0.4,0.51,0.64$, and $0.8 \mathrm{kHz}$ and mixed with the lowpass filtered speech. In tests of consonants perception, frequency lowering improved stop, fricative, and affricate consonant discrimination from 36\% to $46 \%$ across the group when compared with lowpass filtered speech with no frequency lowering. Unfortunately, this improvement in intelligibility for higher frequency sounds was at the expense of lower frequency sounds (Stewart, Strong, \& Palmer, 1976). Whereas the perception of higher-frequency consonants was improved, performance was impaired for nasals and semivowels (Posen et al., 1993). The frequency-lowered signal appeared to be masking important low-frequency speech information.

This is likely to be an important factor in why frequency-lowering vocoders haven't shown promising results in hearing-impaired individuals. Ling and Druz (1967) devised a vocoding system in which high frequencies from 2 to $3 \mathrm{kHz}$ were vocoded and presented as modulated pure tones in the frequency range of 0.75 to $1 \mathrm{kHz}$. The authors hoped that the scheme would improve speech discrimination ability in children born with profound hearing loss. Eight children participated in the initial trial, all of whom were HA users and had some measurable hearing thresholds up to $0.5 \mathrm{kHz}$ (Ling, 1968). All participants received speech training and were divided into two groups. Four children received training with the frequency vocoder, and four received training with a conventional HA. Although both groups showed improvements in their ability to discriminate between vowels and consonants, this was attributed directly to the training the children received, and there was no evidence to suggest that the frequency vocoder was more effective than the conventional HA in providing additional speech cues. Subsequent experiments with hearing-impaired children found no improvements in speech discrimination ability for this system when compared with conventional amplification (Ling, 1968; Ling \& Maretic, 1971). When interpreting the results, it should be noted that 
much of the frequency-lowered speech was outside the children's measurable hearing range.

Posen et al. (1993) continued work with the scheme developed by Lippmann (1980) by adjusting the processing so that it only became active when the signal was dominated by high-frequency information. Preliminary testing with this scheme was carried out with two normally hearing participants. Both participants were trained and tested in listening to frequency-lowered and low-pass filtered speech. Discrimination of stops and fricative and affricate sounds improved on average by $9 \%$ for the two individuals with no decrease in performance in nasals and semivowels when compared with the low-pass filtered condition. A strong effect of training was found. Individuals only attained maximum scores in both conditions after receiving approximately 15 hours of training. Results may have been biased in favor of the frequency-lowered condition as this condition was trained second with no repeated measure of the control low-pass filter condition. Scores may therefore reflect a general improvement over time with training. Unfortunately, the scheme was not tested further in hearing-impaired individuals.

Much of the work carried out using frequencylowering vocoders has failed to demonstrate an improvement in speech perception. The processing typically did not distinguish between voiced and unvoiced sounds, which may have sounded very different to natural speech and therefore difficult to recognize and interpret. As mentioned previously, many of the schemes provided high-frequency cues to the detriment of lower frequency cues. For those studies involving hearing-impaired individuals, many of the participants had very little residual hearing above $1 \mathrm{kHz}$, and the processing may well have been outside the audible hearing range.

\section{Slow Playback}

Interested readers should refer to Braida et al. (1979) who provide a comprehensive summary of early studies using slow playback as a method of frequency lowering. As with vocoding, these studies showed no or only a slight improvement in intelligibility when slow-playback speech was compared with traditional amplification (Beasley et al., 1976; Bennett \& Byers, 1967).

More recent work has been published with devices manufactured by AVR Sonovation. These studies had an advantage over earlier work in that participants were able to take the device home, thereby gaining greater listening exposure to the processing. Published data with older versions of the device, known as the TranSonic and ImpaCt DSR675, have reported favorable results in small numbers of congenitally deafened profoundly hearing-impaired children. A case study described a 10-year-old boy with measurable hearing thresholds below $1 \mathrm{kHz}$, fitted with the body-worn Transonic (Rosenhouse, 1990). The boy was given four speech training sessions with the device. After fitting, the child showed improved detection of environmental and Ling sounds. MacArdle et al. (2001) conducted a larger long-term trial in 36 children with prelingual profound hearing loss; 11 children (aged 5.3-12.9 years) used the TranSonic device over 48 months and were evaluated with aided threshold testing, closed-set speech testing, and speech intelligibility ratings. Improved aided thresholds were measured with the Transonic device for the group when compared with thresholds with conventional devices. Four children showed a significant increase in performance from pre- to postfitting on closed-set speech tests. Many of the remaining children discontinued use of the device either because they were being considered for cochlear implantation or for cosmetic reasons. Of the group who showed no improvement in speech scores, three of the children showed vowel confusions when wearing the device, indicating that the processing may have been affecting lower frequency components of speech. An important limitation of the study was that the participating children had profound hearing losses, and few were oral communicators. The small subgroup of children who did perform well with the device had better hearing in comparison with the rest of the group with aided soundfield hearing thresholds at $1 \mathrm{kHz}$ of $60 \mathrm{dBA}$ or better. In addition, these four children showed lower aided thresholds at 0.25 and $0.5 \mathrm{kHz}$ with the TranSonic in comparison with the rest of the group.

Miller-Hansen, Nelson, Widen, and Simon (2003) carried out a postanalysis of fitting the AVR ImpaCT to a group of 78 congenitally deafened children, ranging in age from 5 to 21 years. Of these, 19 had also been fitted previously with a conventional device, whose performance was compared with that of ImpaCT. Pure-tone average aided thresholds were improved by $11 \mathrm{~dB}$ for the group with ImpaCT. In all, 16 of the children were able to participate in word recognition testing, and their scores with a conventional device were compared with scores with ImpaCT after 1 month of take-home use. For these 16 children, half the group showed an improvement 
in word scores of $10 \%$ or greater when wearing ImpaCT. Analysis found that the group who showed significant improvements with the device were poorer conventional-device users in comparison with the group who showed no improvement.

Following a similar study design, Parent, Chmiel, and Jerger (1997) fitted four adults with severe-toprofound hearing loss with the TranSonic device. All participants were HA users and were given 4 to 6 weeks take-home use with the device. Two of the four participants demonstrated greater sentence understanding in quiet with the device. McDermott, Dorkos, Dean, and Ching (1999) tested five HA users with profound losses above $1 \mathrm{kHz}$. Participants had 12 weeks listening experience with the TranSonic, during which time the device parameters were systematically adjusted. Speech testing using sentence lists and consonants was counterbalanced in an $\mathrm{ABA}$ design with condition A corresponding to the conventional device and condition $\mathrm{B}$ corresponding to the TranSonic. Four of the participants obtained significantly higher scores with the TranSonic device on one or both of the speech measures, ranging from 10 to $30 \%$. However, the authors suggested that the amplification characteristics of the TranSonic in the low frequencies, rather than its frequency-lowering characteristics, may have provided most of the benefit. The TranSonic provided greater audibility in the low frequencies when compared with the participants' conventional devices. Only two participants appeared to obtain additional speech information specifically from the high-frequency signal components after they were lowered. The low-frequency amplification boost the device provided may also have contributed the positive benefits reported by Miller-Hansen et al. (2003) and MacArdle et al. (2001) because improved aided thresholds were reported in both studies when children were wearing the TranSonic or ImpaCT. A follow-up trial (McDermott \& Knight, 2001) with the AVR ImpaCt hearing instrument found little difference in performance between the ImpaCt aid and three participants' own conventional aids. In addition, participants' understanding of sentences in competing noise was significantly poorer with the ImpaCt.

In a recent study, the AVR Nano Xp was trialed in 6 adult participants with steeply sloping losses (Gifford, Dorman, Spahr, \& McKarns, 2007). Participants were required to have hearing thresholds of $60 \mathrm{~dB} H \mathrm{HL}$ or better at frequencies less than or equal to $0.5 \mathrm{kHz}$. Hearing thresholds above $2 \mathrm{kHz}$ were above $80 \mathrm{~dB}$ HL. Speech performance measures included monosyllabic words and sentences in quiet as well as sentences in noise. Participants were required to wear the Nano Xp during a 5-week takehome period, at which point speech testing was carried out with the device. Two of the six participants showed statistically significant improvements with monosyllabic words and sentences in noise measures, with an average performance gain of $17 \%$ when compared with their conventional devices.

The above studies differ with respect to design and testing material. However, taken together, 13 out of 28 children and 6 out of 18 adults were reported to show significant speech benefits from wearing these devices, with performance improvements in words or sentences ranging from $10 \%$ to $20 \%$. Unfortunately, the low-frequency characteristics of the devices have made it problematical to compare slow playback with conventional amplification as many studies have shown an advantage for the slow-playback devices in the amount of lowfrequency amplification gain provided to participants.

\section{Transposition}

As described earlier, the first devices incorporating transposition were the Oticon TP 72 and FRED. Initial studies in nine children with severe hearing loss found no significant improvements in speech intelligibility with the Oticon TP 72 (Foust \& Gengel, 1973; Ling, 1968). FRED, developed by Velmans (1973, 1974), reportedly improved the consonant recognition score in 16 normally hearing adults by $20 \%$ under conditions of simulated hearing loss (Velmans, 1973) and articulation of speech in 6 severely hearing-impaired children (Velmans, 1975). Eight congenitally deafened children, aged 7 to 15 years, demonstrated an increased ability to detect the presence of high-frequency consonants when FRED was enabled (Rees \& Velmans, 1993).

Subjective preferences for FRED were studied with 36 hearing-impaired adults with a variety of sensorineural hearing losses (Velmans \& Marcuson, 1983). Participants were instructed to subjectively select a condition under which processed consonant stimuli sounded most clear and could select from conventional amplification, FRED, or the Oticon TP 72. Twenty-four participants selected FRED, and 10 participants selected conventional amplification. No participant selected the Oticon TP 72. Unfortunately, it is unknown whether these preferences 
resulted from increased speech intelligibility or whether other perceptions may have affected participants' selections.

The processing used by FRED may have the disadvantage of losing some perceptual information because the frequency ratios in the high-frequency band were not preserved when shifted to lower frequencies. As in the case of the Oticon TP 72 developed by Johansson (1961), it is possible that these earlier schemes may have provided some additional high-frequency information at the expense of other perceptual cues by overlapping the shifted and unshifted signals.

The Widex Inteo's AE incorporates linear frequency transposition (Kuk, 2007; Kuk et al., 2006; Kuk, Keenan, et al., 2007). The device was tested in 13 adults with moderate to severe hearing loss above $2 \mathrm{kHz}$ (Kuk, Peeters, Keenan, \& Lau, 2007). A starting frequency of $4 \mathrm{kHz}$ was selected for 12 participants, and the remaining participants had a starting frequency of $3.2 \mathrm{kHz}$. Tests of consonant and vowel discrimination were carried out at 30 and $50 \mathrm{~dB}$ HL during the initial fitting appointment with and without AE enabled. Significant group improvements were reported with an average improvement in consonant discrimination of $6 \%$ at $30 \mathrm{~dB}$ HL and $4 \%$ at $50 \mathrm{~dB}$ HL. Individual results were not shown, so it is unknown how many participants in the group benefited from AE enabled. Participants were given the AE program to take home and try for 2 weeks, after which testing was carried out once again. No, conclusions can be drawn from this second set of testing as not all participants were included for all conditions. Only eight participants were tested at 30 $\mathrm{dB}$ HL and only five were tested at $50 \mathrm{~dB}$ HL.

Subjective results with AE were reported for 16 participants with varying degrees of high-frequency hearing loss (Kuk, Peeters, et al., 2007). Participants were played extracts of bird song, music, and speech with and without the $\mathrm{AE}$ processing enabled and were asked which one they preferred listening to; 12 of the 16 participants selected the $\mathrm{AE}$ processing extract more than $50 \%$ of the time (above chance scores) for bird song. Eight participants selected the AE processing (above chance scores) when listening to music and four participants when listening to speech. The processing implemented in $\mathrm{AE}$ is promising, but larger, more rigid clinical trials are required before conclusions can be drawn about the benefits provided by the device.
In a further study, seven participants with known high-frequency dead regions were presented frequency-transposed sound (Robinson et al., 2007). The term dead region was coined to define a certain region of the cochlea with nonfunctioning inner hair cells (Moore \& Glasberg, 1997; Thornton \& Abbas, 1980). Individuals with no dead regions should obtain a benefit from high-frequency amplification, whereas individuals with dead regions may show no benefit from high-frequency amplification (Baer et al., 2002; Vickers et al., 2001). The edge frequency (fe) of the dead region was confirmed with the TEN test (Moore, Huss, Vickers, Glasberg, \& Alcantara, 2000) and psychophysical tuning curves (Sek, Skrodzka, \& Moore, 2003). The cutoff frequency for transposition was based on the assumption that participants with dead regions benefit from amplification up to one octave above the edge frequency of the dead region (Vickers et al., 2001). For this reason a frequency band well within the dead region (2fe$2.7 \mathrm{fe}$ ) was transposed into a frequency band just above the edge frequency (fe-1.7fe) of the dead region and overlapped with speech that was low-pass filtered at $1.7 \mathrm{fe}$. Frequencies below the edge frequency were amplified but not transposed, and transposition only occurred if the incoming signal was dominated by high frequencies. Participants were presented with a control signal, which consisted of low-pass filtered speech and the transposed signal. All participants had up to 8 hours of training with the transposed signal before testing took place. In a test of consonant identification, four of the seven participants showed improved discrimination of affricate sounds by roughly $20 \%$ when listening to the transposed signal. At the time of writing, the scheme has not been implemented in a take-home device.

\section{Frequency Compression}

In comparison with other methods of frequency lowering, a relatively straightforward means of achieving frequency shifting involves lowering all frequency components downward by a constant factor. For reference, a linear frequency shift by a factor of 0.5 would result in the signal being lowered in frequency by one octave. For normally hearing children and adults, performance on speech perception remains relatively stable with frequency-lowering factors of up to 0.7 (Daniloff, Shriner, \& Zemlin, 1968; 
Nagafuchi, 1976). Frequency shifts greater than this result in a degradation in performance. This is also true for hearing-impaired participants as shown in experiments in which linear frequency shifting has been attempted. In one such test, there were 15 participants with hearing losses better than $40 \mathrm{~dB}$ HL for frequencies below $1 \mathrm{kHz}$ and thresholds greater than $50 \mathrm{~dB}$ HL for frequencies above $1 \mathrm{kHz}$ (Turner \& Hurtig, 1999). Participants were trained and tested in nonsense consonant-vowel speech stimuli using both male and female talkers. Stimuli were lowered in frequency by factors of 0.9, 0.8, 0.7, 0.6 , and 0.5 . When listening to the female talker, 7 participants showed significant improvements of $7 \%$ on average when listening to the frequency-lowered speech. Only three participants showed significant improvements when listening to the male talker. The best results were found at higher lowering factors of $0.7,0.8$, and 0.9 . In another study, a group of four participants with steeply sloping hearing losses and five participants with normal hearing underwent training on speech that had been proportionally shifted in frequency by a factor of 0.6 (McDermott \& Dean, 2000). The hearing-impaired participants had hearing thresholds in their better ear of $40 \mathrm{~dB}$ HL or better at frequencies at and below $0.5 \mathrm{kHz}$. Participants attended 10 weekly sessions of 1 hour duration and were trained in transposed speech material different from that used in testing. For testing, monosyllabic word lists spoken by a female speaker were presented to participants with and without frequency shifting. Participants' scores remained relatively stable across sessions, and despite training, no significant differences were reported in participants' abilities to perceive speech when frequency shifting was enabled. The results of these two studies may have differed because of the training methods used as well as the selection of frequency-lowering factors.

Nonlinear frequency shifting or compression applies increasing amounts of frequency lowering to relatively high input frequencies (Sekimoto \& Saito, 1980). The frequency at which frequency lowering begins is variable, and often, the low frequencies are unchanged by the processing. An early frequency compression scheme was tested by Sakamoto, Goto, Tateno, and Kaga (2000) on 11 adult participants with profound hearing loss above $0.5 \mathrm{kHz}$. Participants wore the portable device at home for 1 to 2 weeks before testing was carried out. For the five individuals who could participate in speech testing, no statistically significant improvements in speech discrimination with the frequency compression device were found (Sakamoto et al., 2000). However, five of the participants were reported to like the device and continued to wear it after the study was completed. As for many earlier studies carried out with frequency-lowering schemes, these participants had very limited acoustic hearing. An additional limitation was that speech scores were near chance levels for the small number of participants who could participate in speech testing.

The perceptual performance of a number of linear and nonlinear frequency compression schemes was evaluated by Reed, Hicks, Braida, and Durlach (1983). In a preliminary study, six participants with normal hearing participated in experiments that investigated whether any of the schemes could improve the discriminability of consonant stimuli. Although none of the schemes provided better performance than a standard condition that applied only low-pass filtering to the stimuli, the best scheme was found to be a variant that progressively increased the amount of frequency compression for input frequencies above approximately $1.2 \mathrm{kHz}$. Lower input frequencies were hardly changed by the processing. This scheme was one of two variants subsequently tested with four hearing-impaired participants who had moderate degrees of hearing loss from $2 \mathrm{kHz}$ onward (Reed, Schultz, Braida, \& Durlach, 1985). Consonant identification testing did not show any advantage for the frequency compression scheme when compared with linear amplification. Overall, these findings suggested that although frequency compression did not provide a perceptual benefit, the scheme that resulted in the best scores for the consonant tests applied nonlinear frequency compression to the higher frequencies while leaving lower frequencies unchanged.

Advantages for such a scheme include no overlap between the shifted and unshifted signals. Lowand mid-frequency information remains preserved as all the first-formant frequency range is left unchanged by the processing. However, the nonlinearity of the compression means that frequency ratios for those compressed high frequencies are not preserved. Speech perception could therefore be negatively affected if the cutoff frequency of compression is decreased to include lower frequencies. 
Nonlinear frequency compression was subsequently investigated by Simpson, Hersbach, and McDermott (2005) with 17 experienced HA users with moderate to profound sensorineural hearing loss. High frequencies above a programmable cutoff were compressed nonlinearly, resulting in those parts of the input signal being shifted to lower frequencies. Signals were amplified with no frequency compression below the cutoff frequency. As progressively larger shifts were applied to components having increasingly higher frequencies, a wide range of high-frequency input signals resulted in a narrower range of output signals. Both the cut-off frequency and degree of compression, or compression ratio, were adjustable in the scheme. The audiogram was used to select an individual cutoff frequency for each participant, and the loudness of the frequency compressed signals was approximately equalized across frequency.

The scheme was implemented in a body-worn device, which participants used daily for 4 to 5 weeks. Monosyllabic word test scores were compared for a conventional hearing device and the frequency compression device. Across the 17 participants, 8 obtained a significant phoneme score increase for the frequency compression scheme over the conventional hearing device. The group showed a statistically significant mean improvement of $6 \%$ for phoneme scores. Disappointingly, a follow-up study in 7 participants with steeply sloping losses found no significant difference in scores across the group between the conventional device and the frequency compression scheme (Simpson, Hersbach, \& McDermott, 2006). As discussed later, for participants with steeply sloping losses and participants with limited acoustic hearing, there is a relatively narrow bandwidth of usable hearing. Frequencylowering schemes attempt to add a large amount of additional information onto this narrow bandwidth, which may not always be successful. The difference in results between the two studies may have been because of different audiogram configurations between the participant groups as well as the fitting methods used. Apart from the cutoff frequency, the fitting parameters were not individually chosen, which could have improved benefit for persons using the device.

In addition, Simpson et al. (2006) reported some consonant confusions for the frequency compression scheme and surmised that participants may be hearing more fricative-like sounds with frequency lowering but not necessarily be able to identify these correctly on every presentation in a test such as consonant identification. Sounds such as /s/ and /sh/ are distinguishable from each other partly by frequency information, with most of the spectral energy in /s/ found beyond $4 \mathrm{kHz}$, whereas most of the energy found in $/ \mathrm{sh} /$ is beyond $2.5 \mathrm{kHz}$ (Borden \& Harris, 1980). Overly aggressive frequency compression has been shown to distort the cues helpful in distinguishing between these two phonemes (Scollie et al., 2009). In this way, perceptual improvements for certain sounds with frequency-lowering schemes can occur at the expense of other sounds.

Scollie et al. (2009) investigated a method for selection of the cutoff frequency and compression ratio for the nonlinear frequency compression scheme described by Simpson et al. (2005). The study evaluated using the audibility of $/ \mathrm{s} /$ and $/ \mathrm{sh} /$ and vowel sound quality as factors in selecting individualized fitting frequency compression parameters. In this way, the authors hoped to maximize the potential benefits of frequency compression, such as audibility of high-frequency sounds, and minimize potential negative effects, such as vowel confusion and adverse sound quality. If the participant was unable to identify $/ \mathrm{s} /$ and $/ \mathrm{sh} /$, the frequency compression was judged to be ineffective, and adjustments were made to either increase the compression ratio or reduce the cutoff frequency in a systematic manner. Similarly, if the participant reported adverse sound quality or vowel confusions, the frequency compression was reduced by increasing the cutoff frequency or reducing the compression ratio. Care was taken in minimizing /s/ and $/ \mathrm{sh} /$ confusions by ensuring that there was no spectral overlap between the two sounds when frequency compression was enabled.

Using these fitting methods, the scheme was subsequently implemented into a prototype BTE $\mathrm{HA}$, and further testing was carried out in 11 children and 13 adults with hearing loss (Glista, Scollie, Bagatto, Seewald, \& Johnson, 2009). Participants wore the frequency compression device in their daily lives over a period of 4 weeks. All the children and 8 of the 13 adult participants showed statistically significant improved speech perception on at least one speech measure when compared with conventional amplification, with a total of 9 children and 8 adult participants showing an improved ability in plural recognition; 7 children and 2 adult participants 


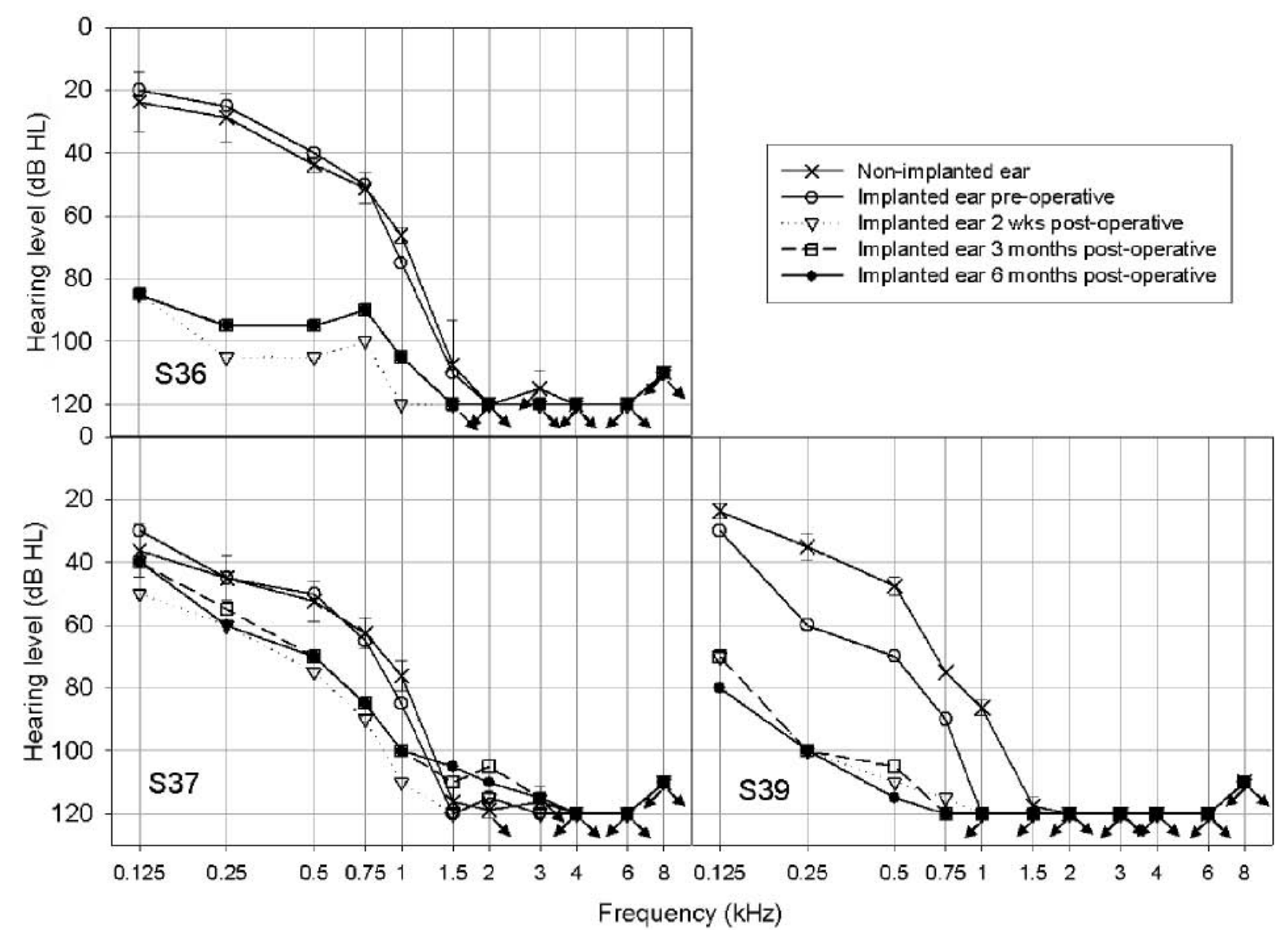

Figure 3. Pre- and postoperative audiogram results for the three individuals who participated in the study. Error bars indicate one standard deviation. Arrows indicate levels that were limited by the maximum output of the audiometer.

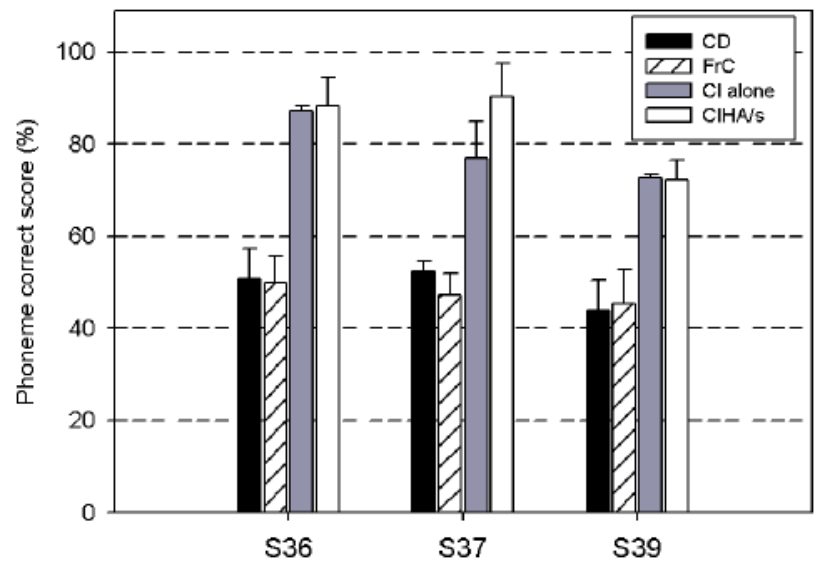

Figure 4. Phoneme scores for a monosyllabic word test for the three individuals who participated in the study. Participants had been wearing their cochlear implants for 6 months at the time of testing. Error bars indicate one standard deviation. indicated that they subjectively preferred the sound quality of the frequency compression scheme when compared with conventional amplification. The child participants seemed to gain greater benefits with the device as a larger majority of the children's group demonstrated improved outcomes on both objective and subjective measures. The authors hypothesized that the reason for this may be that children are more adaptable HA users than adults and are, therefore, more readily able to accommodate for changes to the programming of their HAs.

Clinical outcomes using these methods were highly successful, with $69 \%$ of adult users and $91 \%$ of child users obtaining benefit when using the frequency compression device. Thus far, nonlinear frequency compression has been reportedly trialed and tested on speech perception measures in 46 adults and 11 children with hearing loss; 16 of the adults and all the children showed statistically significant 


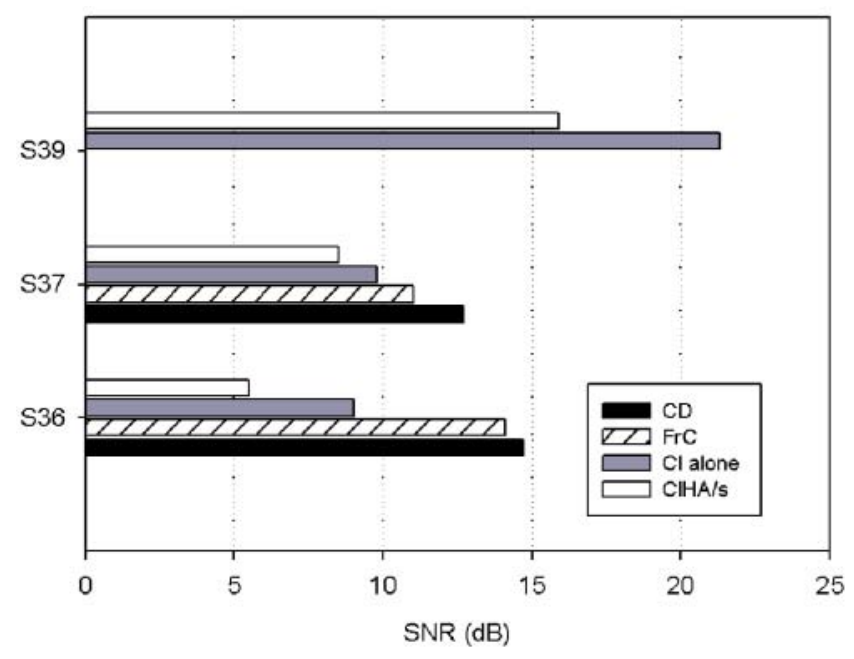

Figure 5. Mean signal-to-noise ratios obtained by the three individuals who participated in the study. Participants had been wearing their cochlear implants for 6 months at the time of testing. Testing could not be carried out for S39 wearing hearing aids as she scored less than $75 \%$ of the words correct in the initial sentence test without competing noise.

improvements on at least one speech measure when frequency compression was enabled.

\section{Future Research Needs}

\section{Candidacy Criteria}

Frequency-lowering schemes are beginning to provide more positive outcomes for users. Many, but not all, individuals have shown perceptual benefits from trialing these schemes. This leads us to the question of which participant groups would make "good" users of frequency-lowering systems. There are doubtless a multitude of factors that could lead to a good user, and the literature may provide clues as to what factors may lead to poorer outcomes. For children and adults with very little measurable hearing, frequency lowering, regardless of the technique implemented, has not provided very favorable results. If the individual is a suitable candidate, cochlear implantation is more likely to be a more suitable rehabilitation choice for individuals with profound hearing loss.

Additionally, the boundary between $\mathrm{HA}$ and cochlear implant (CI) candidacy has been shifting radically in recent years. The selection criteria for implantation have been relaxed to include individuals with more residual hearing (Dettman et al., 2004; Rubinstein, Parkinson, Tyler, \& Gantz, 1999). It is not unusual now for cochlear implantation to be considered for individuals who have on average, near-normal hearing thresholds in the low frequencies, with a sharp drop in thresholds to severeprofound levels for frequencies above $1 \mathrm{kHz}$. The large majority of these individuals showed improvements in speech scores postoperatively when wearing the CI together with HAs (Gantz \& Turner, 2004; Gantz, Turner, Gfeller, \& Lowder, 2005; Gstoettner et al., 2004; James et al., 2005; Skarzynski et al., 2002).

Because of the configuration of the hearing loss in these individuals, conventional HAs have proved limited in their ability to provide adequate highfrequency audibility. In theory, frequency-lowering HAs appear to be a good solution for these individuals, but several studies thus far on frequency shifting with participants with steeply sloping hearing loss have not been favorable (Gifford et al., 2007; McDermott \& Dean, 2000; Simpson et al., 2006). For those individuals in whom improvements were found (Gifford et al., 2007; Robinson et al., 2007), these are potentially smaller performance gains than implantation could provide.

Three of the individuals with steeply sloping hearing loss who participated in the study described by Simpson et al. (2006) went on to receive CIs (Simpson, 2007). These participants were implanted with the Nucleus Freedom Contour Advance system. If useful hearing was present postoperatively, participants were fitted with an in-the-ear HA together with the speech processor in the implanted ear. Figure 3 shows the pre- and postoperative audiograms for the three participants. All participants continued to wear an HA in the contralateral ear, and the implant was programmed to provide the participant with high-frequency information above the frequency at which the acoustic hearing was no longer considered useful. Figures 4 and 5 show phoneme scores on a test of monosyllabic words and signal-to-noise ratios (SNRs), respectively, for a sentence test in competing noise for these three participants at 6 months post-implantation. For the sentence test in noise, an adaptive procedure was used to estimate the SNR for a target score of 50\% correct. Testing in noise was not carried out for S39 preoperatively as she scored less than $75 \%$ correct on sentence testing in quiet.

Participant numbers for the experiment were small, which limits generalizations. However, cochlear implantation appeared to be more effective than frequency compression at providing improved speech perception for these participants in both quiet and 
noise. Phoneme scores increased on average by $30 \%$ from $49 \%$ preoperatively to $79 \%$ postoperatively for the participants when wearing their CIs together with HAs at 6 months postimplantation. Despite the small number of participants, results are similar to past studies on acoustic-electric stimulation, with average word scores improving for the current study from $17 \%$ preoperatively to $66 \%$ postoperatively as compared with $25 \%$ to $73 \%$ pre- to postoperatively for a group of eight acoustic-electric users (Gantz et al., 2005) and $7 \%$ to $62 \%$ for a group of 13 acoustic-electric users (Kiefer et al., 2005).

The disappointing results for frequency compression are not so surprising. Considering the hearing loss is severe to profound in the mid-frequencies, frequency lowering of this information begins to interfere with first formant information and sound quality. If only higher-frequency information is shifted to preserve sound quality, it is unlikely that useful information would be provided, and it would be largely inaudible to the person.

Cochlear implantation may provide better outcomes for these individuals, although it is not a viable option for all. For children with residual hearing, in particular, it is not currently routine practice to offer implantation as a rehabilitative option. For adults, a loss of hearing in the implanted ear, general risks of surgery, and the possibility that the electrical stimulation will not provide a meaningful percept are some of the risks the patient must consider. In addition, many patients may not be willing or able to undergo surgery. As HA technology is constantly being updated and improved, patients should be given access to all possible rehabilitative options, and processing such as frequency-lowering devices should certainly be considered.

When deciding whether to try a frequencylowering HA, the clinician should be aware of factors such as the frequency at which the patient's useful hearing ends as well as the steepness of the slope of the audiogram. As a general rule, at least for adults, the lower this frequency and the steeper the slope, the more unlikely it is that frequency lowering would be beneficial.

The devices have yet to be tried with milder high-frequency hearing loss. The typical HA's upper frequency limit may not be high enough to ensure the inclusion of certain high-frequency fricatives in the signal, such as /s/. For example, Stelmachowicz, Pittman, Hoover, and Lewis (2001) evaluated fricative perception for a group of hearing-impaired participants under various low-pass filter conditions. To obtain optimum performance for female and child speakers, it was found that the bandwidth needed was at least $9 \mathrm{kHz}$. These sounds are particularly important in children who are still learning grammatical rules and articulation of sound. For those with mild high-frequency loss or in hearingimpaired children, frequency-lowering devices may be a suitable means of providing these cues by artificially extending the bandwidth of the hearing device. Further research would be required before clinicians could confidently fit frequency-lowering devices in young children who are unable to provide feedback about sound quality.

\section{Training}

Much of the literature describing frequency lowering also incorporates training. Many authors suggest that training is beneficial or necessary for the participant to gain benefit from the device (Braida et al., 1979; Gengel \& Foust, 1975; Kuk, Keenan, et al., 2007; Ling, 1968). The reasons for this are twofold. First, training enables the participant to adjust to the sound quality as the frequency-lowered signal can seem unnatural or strange at first. Second, the participant has to learn to detect and distinguish the additional information in the signal. For example, fricative sounds such as $/ \mathrm{s} / \mathrm{and} / \mathrm{sh} /$ may at first sound like unwanted noise rather than important speech information.

Numerous studies report that frequency lowering together with training can provide improved intelligibility of speech (Biondi \& Biondi, 1973; Ling, 1968; Oeken, 1963). In one study, two normally hearing participants reached optimum stable performance after 15 hours of listening to frequency-lowered speech (Posen et al., 1993). In another study, nine children with severe to profound hearing loss who listened to slow-play speech with training performed better than a hearing-impaired control group who received no training (Beasley et al., 1976). Peak performance for this group ranged from 3 to 7 training sessions, with each session lasting 20 minutes. Turner and Hurtig (1999) found positive results with proportional frequency shifting after training a group of 15 participants with mild to severe hearing loss. Participants were trained and tested by listening to nonsense syllables spoken by a male and female talker. 
At first glance, these results seem encouraging. However, for all these studies, the material used in training was of the same format as that used for testing. Results could therefore be specific to the materials used in the experiments. Training may have resulted in participants performing a specific task better rather than demonstrating an improved understanding of frequency-lowered speech. McDermott and Dean (2000) trained participants using materials different from the test measures and found no significant differences in participants' abilities to perceive speech when frequency shifting was enabled. A similar finding was reported by Velmans (1975) and Blamey, Clark, Tong, and Ling (1990) when hearingimpaired children received articulation training by listening to transposed or cued speech. Improvements were shown for the trained condition but did not extend to speech recognition. Disappointingly, participants appeared unable to generalize the training they received to novel listening conditions. Results demonstrate that it cannot be assumed that training in one set of speech materials will result in spontaneous transfer to another set of materials.

Studies provided, on average, between 10 and 20 hours of listening exposure to frequency-lowered speech. This is a comparatively small amount of time to listen to novel material, especially if one considers how many hours per day a HA wearer uses their device. As frequency-lowering schemes are now in several commercially availably hearing devices, providing listening exposure is less of an issue. What is of interest is whether additional training will help the user adapt more rapidly to the novel signal. In more intensive training regimes unrelated to that of frequency lowering, hearing-impaired participants have demonstrated benefits from auditory training in studies investigating rehabilitation (Sweetow \& Sabes, 2006), and so it is possible that more intensive training with a take-home device may facilitate improved speech perception. However, training together with frequency lowering requires further investigation to determine the length and nature of the training regime that will allow for the development of new sound patterns to be associated with the frequency-lowered signal.

\section{Summary and Conclusions}

Providing high-frequency information successfully is important for both adults and children who use these cues to learn articulation of sounds as well as many grammatical rules. Despite improved technology, today's conventional hearing devices are still far from providing improved speech recognition for severe high-frequency hearing loss. With this challenge in mind, an alternative to current amplification techniques is to shift high-frequency components of a signal into a lower frequency region. These schemes are beginning to show successful outcomes for individuals with high-frequency hearing loss. Candidacy remains unclear, but as a general rule, the devices can be tried with a range of high-frequency losses. Outcomes with steeply sloping losses (defined as little residual hearing above $1 \mathrm{kHz}$ ) and profound hearing loss have not been as favorable. It has been suggested that children in particular may benefit from these schemes. Fitting strategies are currently being investigated and are tending toward individualized optimization to ensure increased access to high-frequency consonant sounds as well as acceptable sound quality. Finally, there is also a strong trend to recommend a period of auditory training to facilitate acclimatization to frequency lowering, but this too requires further evaluation.

\section{Acknowledgments}

The author is especially grateful to Professor Hugh J. McDermott, Dr. Stefan Launer, Adam Hersbach, Dr. John Heaseman, Professor Richard Dowell, Dr. Robert Briggs, and Catherine Sucher who have contributed to this work. Thanks also go to Dr. Kevin Munro and Professor Chris Plack for helpful comments on earlier drafts of this article.

\section{References}

Baer, T., Moore, B. C., \& Kluk, K. (2002). Effects of low pass filtering on the intelligibility of speech in noise for people with and without dead regions at high frequencies. Journal of the Acoustical Society of America, 112, 1133-1144.

Beasley, D. S., Mosher, N. L., \& Orchik, D. J. (1976). Use of frequency-shifted/time-compressed speech with hearingimpaired children. Audiology, 15, 395-406.

Bennett, D. S., \& Byers, V. W. (1967). Increased intelligibility in the hypacusic by slow-play frequency transposition. Journal of Auditory Research, 7, 107-118.

Biondi, E., \&Biondi, L. (1973). The sampling of sounds as a new means of making speech intelligible to the deaf: Theories and results. At the Carnahan conference on electronic prosthesis, University of Kentucky. pp. 5-9. 
Blamey, P. J., Clark, G. M., Tong, Y. C., \& Ling, D. (1990). Perceptual-oral training of two hearing-impaired children in the recognition and production of $/ \mathrm{s} /$ and /z. British Journal of Audiology, 24, 375-379.

Borden, G. J., \& Harris, K. S. (1980). Speech science primer. Baltimore: Williams \& Wilkins.

Braida, L. D., Durlach, N. I., Lippmann, R. P., Hicks, B. L., Rabinowitz, W. M., \& Reed, C. M. (1979). Hearing aids: A review of past research on linear amplification, amplitude compression, and frequency lowering. Rockville, MD: ASLHA.

Ching, T. Y., Dillon, H., \& Byrne, D. (1998). Speech recognition of hearing-impaired listeners: Predictions from audibility and the limited role of high-frequency amplification. Journal of the Acoustical Society of America, 103, $1128-1140$.

Daniloff, R. G., Shriner, T. H., \& Zemlin, W. R. (1968). Intelligibility of vowels altered in duration and frequency. Journal of the Acoustical Society of America, 44, 700-707.

Davis, A. (1995). Hearing in adults. London: Whurr.

Davis, W. (2001). Proportional frequency compression in hearing instruments. Hearing Review, February, 34-39.

Denes, P. B. (1967). On the motor theory of speech perception. Cambridge, MA: MIT Press.

Dettman, S. J., D’Costa, W. A., Dowell, R. C., Winton, E. J., Hill, K. L., \& Williams, S. S. (2004). Cochlear implants for children with significant residual hearing. Archives of Otolaryngol-Head E Neck Surgery, 130, 612-618.

Dudley, H. (1939). Remaking speech. Journal of the Acoustical Society of America, 11, 165.

Foust, K. O., \& Gengel, R. W. (1973). Speech discrimination by sensorineural hearing-impaired persons using a transposer hearing aid. Scandinavian Audiology, 2, 161-170.

Gantz, B. J., \& Turner, C. (2004). Combining acoustic and electrical speech processing: Iowa/Nucleus hybrid implant. Acta Oto-laryngologica, 124, 344-347.

Gantz, B. J., Turner, C., Gfeller, K. E., \& Lowder, M. W. (2005). Preservation of hearing in cochlear implant surgery: Advantages of combined electrical and acoustical speech processing. Laryngoscope, 115, 796-802.

Gengel, R. W., \& Foust, K. O. (1975). Some suggestions on how to evaluate a transposer hearing aid. Journal of Speech and Hearing Disorders, 40, 206-210.

Gifford, R. H., Dorman, M. F., Spahr, A. J., \& McKarns, S. A. (2007). Effect of digital frequency compression (DFC) on speech recognition in candidates for combined electric and acoustic stimulation (EAS). Journal of Speech Language and Hearing Research, 50, 1194-1202.

Glista, D. A., Scollie, S., Bagatto, M., Seewald, R., \& Johnson, A. (2009). Evaluation of nonlinear frequency compression II: Clinical outcomes. Manuscript submitted for publication.

Gstoettner, W., Kiefer, J., Baumgartner, W. D., Pok, S., Peters, S., \& Adunka, O. (2004). Hearing preservation in cochlear implantation for electric acoustic stimulation. Acta Oto-laryngologica, 124, 348-352.
Hogan, C. A., \& Turner, C. W. (1998). High-frequency audibility: Benefits for hearing-impaired listeners. Journal of the Acoustical Society of America, 104, 432-441.

James, C., Albegger, K., Battmer, R., Burdo, S., Deggouj, N., Deguine, O., et al. (2005). Preservation of residual hearing with cochlear implantation: How and why. Acta Oto-laryngologica, 125, 481-491.

Johansson, B. (1961). A new coding amplifier system for the severely hard of hearing. Proceedings of the $3 \mathrm{rd}$ International Congress on Acoustics, Stuttgart 1959, 2, 655-657.

Kiefer, J., Pok, M., Adunka, O., Sturzebecher, E., Baumgartner, W., Schmidt, M., et al. (2005). Combined electric and acoustic stimulation of the auditory system: results of a clinical study. Audiology \& Neuro-otology, 10, 134-144.

Kuk, F. (2007). Critical factors in ensuring efficacy of frequency transposition Part 1: Individualizing the start frequency. Hearing Review, 14, 60-67.

Kuk, F., Keenan, D., Peeters, H., Lau, C., \& Crose, B. (2007, April). Critical factors in ensuring efficacy of frequency transposition Part 2: Facilitating initial adjustment. Hearing Review, 14. Retrieved April 14, 2009, from http://www.hearingreview.com/issues/articles/ 2007-04_07.asp

Kuk, F., Korhonen, P., Peeters, H., Keenan, D., Jessen, A., \& Anderson, H. (2006). Linear frequency transposition: Extending the audibility of high-frequency information. Hearing Review, 13, 42-48.

Kuk, F., Peeters, H., Keenan, D., \& Lau, C. (2007). Use of frequency transposition in a thin-tube open-ear fitting. Hearing Journal, 60, 59-63.

Ling, D. (1968). Three experiments on frequency transposition. American Annals of the Deaf, 113, 283-294.

Ling, D., \& Druz, W. S. (1967). Transposition of highfrequency sounds by partial vocoding of the speech spectrum. Journal of Auditory Research, 7, 133-144.

Ling, D., \& Maretic, H. (1971). Frequency transposition in the teaching of speech to deaf children. Journal of Speech and Hearing Research, 14, 37-46.

Lippmann, R. P. (1980). Perception of frequency lowered speech. Journal of the Acoustical Society of America, $67, \mathrm{~S} 78$.

MacArdle, B. M., West, C., Bradley, J., Worth, S., Mackenzie, J., \& Bellman, S. C. (2001). A study of the application of a frequency transposition hearing system in children. British Journal of Audiology, 35, 17-29.

McDermott, H. J., \& Dean, M. R. (2000). Speech perception with steeply sloping hearing loss: Effects of frequency transposition. British Journal of Audiology, 34, 353-361.

McDermott, H. J., Dorkos, V. P., Dean, M. R., \& Ching, T. Y. (1999). Improvements in speech perception with use of the AVR TranSonic frequency-transposing hearing aid. Journal of Speech, Language, and Hearing Research, 42, 1323-1335.

McDermott, H. J., \& Knight, M. R. (2001). Preliminary results with the AVR ImpaCt frequency-transposing 
hearing aid. Journal of the American Academy of Audiology, 12, 121-127.

Miller-Hansen, D. R., Nelson, P. B., Widen, J. E., \& Simon, S. D. (2003). Evaluating the benefit of speech recoding hearing aids in children. American Journal of Audiology, 12, 106-113.

Moore, B. C. J., \& Glasberg, B. R. (1997). A model of loudness perception applied to cochlear hearing loss. Auditory Neuroscience, 3, 289-311.

Moore, B. C., Huss, M., Vickers, D. A., Glasberg, B. R., \& Alcantara, J. I. (2000). A test for the diagnosis of dead regions in the cochlea. British Journal of Audiology, 34, 205-224.

Murray, N., \& Byrne, D. (1986). Performance of hearingimpaired and normal hearing listeners with various high frequency cut-offs in hearing aids. Australian Journal of Audiology, 8, 21-28.

Nagafuchi, M. (1976). Intelligibility of distorted speech sounds shifted in frequency and time in normal children. Audiology, 15, 326-337.

Neary, T. (1989). Static, dynamic, and relational properties in vowel perception. Journal of the Acoustical Society of America, 85, 2088-2113.

Oeken, F. W. (1963). Frequency transposition for hearing improvement in internal ear deafness. Archiv für Ohren-, Nasen- und Kehlkopfheilkunde, 181, 418-425.

Parent, T. C., Chmiel, R., \& Jerger, J. (1997). Comparison of performance with frequency transposition hearing aids and conventional hearing aids. Journal of the American Academy of Audiology, 8, 355-365.

Posen, M. P., Reed, C. M., \& Braida, L. D. (1993). Intelligibility of frequency-lowered speech produced by a channel vocoder. Journal of Rehabilitation and Research Development, 30, 26-38.

Rankovic, C. M. (1991). An application of the articulation index to hearing aid fitting. Journal of Speech and Hearing Research, 34, 391-402.

Reed, C. M., Hicks, B. L., Braida, L. D., \& Durlach, N. I. (1983). Discrimination of speech processed by low-pass filtering and pitch-invariant frequency lowering. Journal of the Acoustical Society of America, 74, 409-419.

Reed, C. M., Schultz, K. I., Braida, L. D., \& Durlach, N. I. (1985). Discrimination and identification of frequencylowered speech in listeners with high-frequency hearing impairment. Journal of the Acoustical Society of America, $78,2139-2141$

Rees, R., \& Velmans, M. (1993). The effect of frequency transposition on the untrained auditory discrimination of congenitally deaf children. British Journal of Audiology, $27,53-60$.

Robinson, J. D., Baer, T., \& Moore, B. C. (2007). Using transposition to improve consonant discrimination and detection for listeners with severe high-frequency hearing loss. International Journal of Audiology, 46, 293-308.
Rosenhouse, J. (1990). A new transposition device for the deaf. Hearing Journal, 43, 20-25.

Rubinstein, J. T., Parkinson, W. S., Tyler, R. S., \& Gantz, B. J. (1999). Residual speech recognition and cochlear implant performance: Effects of implantation criteria. American Journal of Otology, 20, 445-452.

Sakamoto, S., Goto, K., Tateno, M., \& Kaga, K. (2000). Frequency compression hearing aid for severe-toprofound hearing impairments. Auris Nasus Larynx, 27, 327-334.

Scollie, S., Parsa, V., Glista, D. A., Bagatto, M., Wirtzfeld, M., \& Seewald, R. (2009). Evaluation of nonlinear frequency compression I: Fitting rationale. Manuscript submitted for publication.

Sek, A., Skrodzka, E., \& Moore, B. (2003). Development of a fast method for determining psychophysical tuning curves. Journal of the Acoustical Society of America, 113, 2287-2288.

Sekimoto, S., \& Saito, S. (1980). Nonlinear frequency compression speech processing based on the PAR-COR analysis-synthesis technique. Annual Bulletin Research Institute of Logopedics and Phoniatrics, 14, 65-72.

Simpson, A. (2007). Improving high-frequency audibility for hearing-impaired listeners using a cochlear implant or frequency-compression aid. Unpublished doctoral dissertation, University of Melbourne, Melbourne, Australia.

Simpson, A., Hersbach, A. A., \& McDermott, H. J. (2005). Improvements in speech perception with an experimental nonlinear frequency-compression hearing device. International Journal of Audiology, 44, 281-292.

Simpson, A., Hersbach, A. A., \& McDermott, H. J. (2006). Frequency compression outcomes for listeners with steeply sloping audiograms. International Journal of Audiology, 45, 619-629.

Skarzynski, H., Lorens, A., D’Haese, P., Walkowiak, A., Piotrowska, A., Sliwa, L., et al. (2002). Preservation of residual hearing in children and post-lingually deafened adults after cochlear implantation: An initial study. ORL: Journal for Oto-rhino-laryngology and Its Related Specialties, 64, 247-253.

Stelmachowicz, P. G., Pittman, A. L., Hoover, B. M., \& Lewis, D. E. (2001). Effect of stimulus bandwidth on the perception of $/ \mathrm{s} /$ in normal- and hearing-impaired children and adults. Journal of the Acoustical Society of America, 110, 2183-2190.

Stewart, S. E., Strong, W. J., \& Palmer, E. P. (1976). Experiments on the intelligibility of speech codes for the severely hearing impaired. Journal of the Acoustical Society of America, 60, S124.

Sweetow, R. W., \& Sabes, J. H. (2006). The need for and development of an adaptive Listening and Communication Enhancement (LACE) Program. Journal of the American Academy of Audiology, 17, 538-558.

Thornton, A. R., \& Abbas, P. J. (1980). Low-frequency hearing loss: Perception of filtered speech, psychophysical 
tuning curves, and masking. Journal of the Acoustical Society of America, 67, 638-643.

Turner, C. W., \& Hurtig, R. R. (1999). Proportional frequency compression of speech for listeners with sensorineural hearing loss. Journal of the Acoustical Society of America, 106, 877-886.

Velmans, M. (1973). Speech imitation in simulated deafness, using visual cues and "recoded" auditory information. Language and Speech, 16, 224-236.

Velmans, M. (1974). The design of speech recoding devices for the deaf. British Journal of Audiology, 8, 1-5.
Velmans, M. (1975). Effects of frequency "recoding" on the articulation learning of perceptively deaf children. Language and Speech, 18, 180-193.

Velmans, M., \& Marcuson, M. (1983). The acceptability of spectrum-preserving and spectrum-destroying transposition to severely hearing-impaired listeners. British Journal of Audiology, 17, 17-26.

Vickers, D. A., Baer, T., \& Moore, B. C. J. (2001). Effects of lowpass filtering on speech intelligibility for listeners with dead regions at high frequencies. British Journal of Audiology, 35, 148-149.

For reprints and permissions queries, please visit SAGE's Web site at http://www.sagepub.com/journalsPermissions.nav 